\title{
Correction to: Film and the Other Video Contents (TV program and Internet Video)
}

\author{
Takashi Uchiyama
}

\section{Correction to:}

Chapter "Film and the Other Video Contents (TV program and Internet Video)" in: M. Sugaya (ed.), Perspectives on the Japanese Media and Content Policies, Advances in Information and Communication Research 2, https://doi.org/10.1007/978-981-15-4704-1_7

The original version of this book was inadvertently published with the information about the orange line missed out in Figure 1. The figure has been updated with the correct version as in below: 


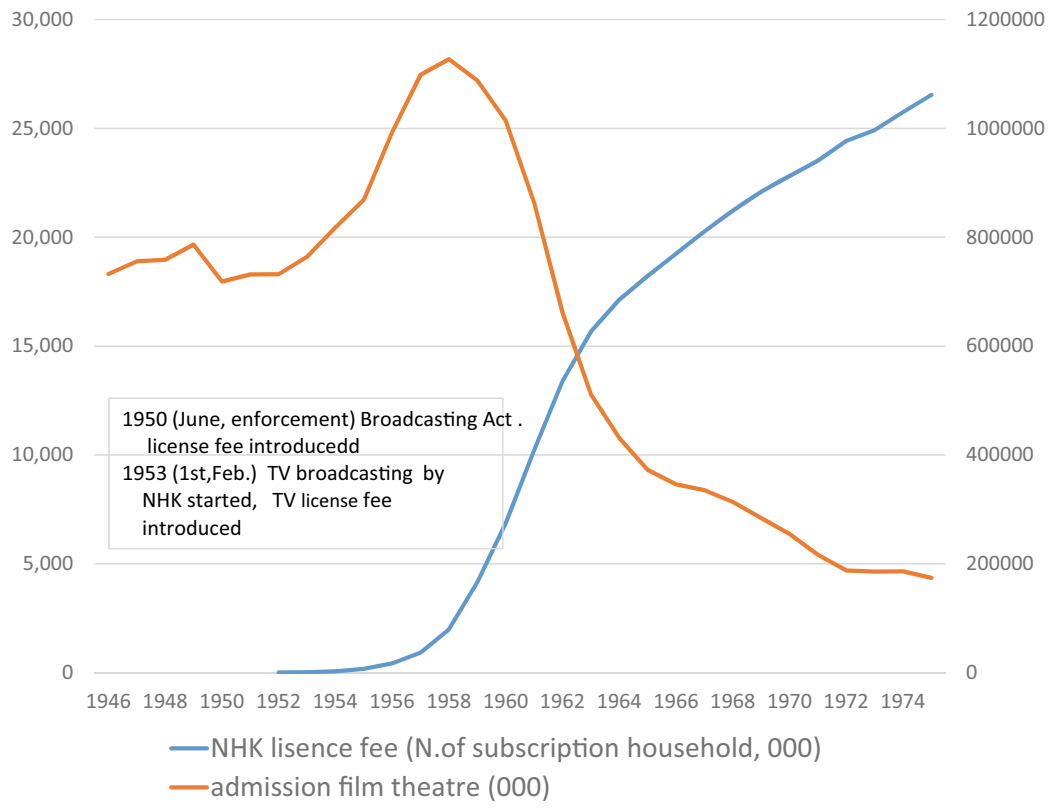

Fig. 1 Diffusion of TV and decline of cinema. (Data Source) NHK lisence fee from MIC Longterm time series data. Theatre admission from Motion Picture Producers Association of Japan, Inc. (Graphic) by author 